\title{
Çok Nitelikli Fayda Teorisi ile CRITIC Yöntem Entegrasyonu: Akıllı Teknoloji Tercih Örneği
}

DOI: $10.26466 /$ opus.584123

\author{
$*$ \\ Berna Bulğurcu* \\ * Dr. Öğr. Üyesi, Çukurova Üniversitesi, İ̈BF, İşletme Bölümü, Adana/Türkiye \\ E-Posta: bkiran@cu.edu.tr \\ ORCID: $\underline{0000-0002-9695-2668}$
}

\section{Öz}

Bu çalşmanın amacı akıllı teknolojik ürünlerden henüz yaygın kullanilmayan akıllı saatlerin tercihinde önemli görülen kriterlerin ortaya konması ve bu kriterlere yönelik gerçekleştirilen değerlendirmeler sonucunda beş farklı akıllı saat markasından kullanıcıya en çok faydayı sağlayan markanın tespit edilmesidir. Tespit ve değerlendirmelerin gerçekleştirilmesinde karar analizinin önemli konularından biri olan Çok Nitelikli Fayda Teorisi (MAUT) ile Kriterler arası Korelasyon Yoluyla Kriterlerin Önem Tespiti (CRITIC) adı verilen ağırlılandırma yönteminin bütünleşik kullanımından yararlanılmıştır. Nicel ve nitel kriterlerin bir araya getirilerek korelasyon analizini temel alan nesnel bir ağırlkklandırma yöntemi ile aralarındaki önem düzeyinin elde ettiğ $i$ sonuca göre akıllı saatlerin sahip olduğu ağırlık özelliği en önemli kriter olarak tespit edilmiştir. Sonrasında sirayla fiyat, depolama alanı, boyut, kullanım kolaylı̆̆ı, sağhlkla ilgili uygulamaları varlığı, marka imajı, estetik görünüm, pil ömrü, tasarım çeşitliliği, sağlamlık ve son sırada ise satış sonrası hizmetler gelmiştir. Tüm bu kriterlerden sağlanan faydanın piyasada satışta olan ve en fazla talep gören Apple, Samsung, Huawei, Fitbit, Xiaomi markaları arasında bir kıyaslaması gerçekleştirilmiş ve Apple markasına ait akıllı saatin kullanıcılara en çok faydayı sağladığı objektif bir değerlendirme ile tespit edilmiştir.

Anahtar Kelimeler: Çok Nitelikli Fayda Teorisi (MAUT), CRITIC, Akıllı teknoloji seçimi 


\title{
Multi-Attribute Utility Theory Integration with CRITIC Method: Smart Technology Preference Example
}

\begin{abstract}
This study aims to determine the criteria that are considered important in the choice of smartwatches which are not yet widely used among the smart technology products and to determine the brand that provides the most benefit to the user from five different smartwatch brands as a result of the evaluations made for these criteria. One of the important issues of decision analysis was the integrated use of Multi-Attribute Utility Theory (MAUT) and Criteria Importance Through Intercriteria Correlation (CRITIC) weighting method. The quantitative and qualitative criteria were combined and the objective weighting method based on correlation analysis yielded the importance of the smartwatch, which is a quantitative criterion, as the most important criterion. Following price, storage space, size, ease of use, presence of health-related applications, brand image, aesthetic appearance, battery life, variety of designs, robustness and after-sales services. The benefits of these criteria have been compared between Apple, Samsung, Huawei, Fitbit, and Xiaomi brands, which are the most in demand in the market, and it is determined by an objective evaluation that Apple brand smartwatch provides the most benefit to the users.
\end{abstract}

Keywords: Multi-Attribute Utility Theory (MAUT), CRITIC, Selection of smart technology 


\section{Giriş}

Endüstri 4.0 ile birlikte daha da gelişen ve farklılaşan akıllı teknolojiler pazarında alternatif ürünler artmaktadır. Akıllı telefon piyasasında yaşanan doygunlukla birlikte, firmalar pazarda hareketlilik sağlamak adına akıllı teknolojik cihazlar geliştirmeye başlamışlar ve akıllı telefonlar ile uyumlu olarak akıllı saatler veya giyilebilir akıllı gözlükler piyasaya sunmuşlardır (Wang, 2015, s.2542).

Uluslararası veri şirketinin (IDC) 2019 yılında yayınladığı rapora göre 2018 yılı akıllı giyilebilir ürün pazar payı rakamlarına göre Apple ve Xiaomi firmaları pazarda öncü firmalar olarak görünürken, hemen artlarından Samsung, Huawei, ve Fitbit firmaları gelmektedir. Piyasadaki diğer üreticilerin pazar paylarını artırmak adına gerçekleştirdikleri faaliyetlerde özellikle tercih edilebilirliği artırmaya yönelik faaliyette bulundukları gözlenmektedir. Suki ve arkadaşlarına (2013) göre akıllı telefonlara uyumlu yeni teknolojilerin sunulması piyasada çeşitliliği artırarak, pazardaki ürün ve marka tercihini kuvvetlendirmeye yönelik faaliyetlerdir. Son yıllarda dikkat çeken yeni teknolojilerden birisi de hem akıllı telefonlar ile uyumlu hem de sağlıkla ilgili yardımcı pek çok özelliği ile dikkat çeken akıllı saat teknolojisidir. Akıllı saat teknolojisinin sundukları aslında müşterilerin akıllı telefon tercihlerini de etkilemeye yöneliktir. Özellikle teknolojinin bütünleşik kullanım avantajı yaratması, tasarım çeşitliliğinin estetik görünümle birleştirilmesi, sağlıkla ilgili uygulamaların etkin kullanılmasına destek olması açısından akıllı saatler tercih edilmeye başlanmıştır.

$\mathrm{Bu}$ çalışmada da akıllı telefonlar ile uyumlu akıllı saatlerin tercih edilmesine yönelik özellikler ortaya konularak değerlendirmeye tabi tutulmuştur. Bir tüketici olarak hangi özelliğin daha fazla üzerinde durarak marka tercihi yapılmasının daha doğru olacağı konusunda karar verilmeye çalışılmış ve üzerinde durulan markaları iyi tanıyan bu alandaki uzmanlar aracıllğı ile nihai seçim önerisinde bulunulmuştur. Karar vermenin, özelliklerin önem düzeylerinin ortaya konulmasının ve karmaşık alternatifler arasında bir sıralama yaparak en iyinin seçilmesinin söz konusu olduğu problem türlerinde en sık başvurulan teori karar teorisi ve teoriye hizmet eden ilgili tekniklerdir. Öyle ki her geçen gün farklı tekniklerle kendini yenileyen ve geliştiren teknikler bütünü olması sebebiyle 
bu problemin çözümünde de bir tarafı çok kriterli ve çok amaçlı karar verme tekniklerine uzanan Çok Nitelikli Fayda Teorisi'nden (MAUT) yararlanılmış ve akıllı saatlere ait niceliksel olmayan özelliklerin nicel hale dönüştürülmesinde kullanılmıştır. Kriterler arası Korelasyon Yoluyla Kriterlerin Önem Tespiti şeklinde açılımı olan ve CRITIC kısaltması ile kullanılan subjektif değerlendirmeden uzak ağırlıklandırma yöntemi ile de yazın incelemesi sonucu belirlenen akıllı saatlerin tercih özelliklerinin önem düzeyleri belirlenmiştir. Tüm bunlara ilaveten, çok nitelikli fayda teorisi bu noktada tekrar devreye girerek en çok faydayı elde edeceği alternatifi seçmek adına, CRITIC ağırlıklandırma tekniği ile kriterlere ait göreceli önem değerlerini kullanarak en faydalı alternatif önerisini sunmuştur.

Çalışmaya ait bölüm planında giriş bölümünün ardından, ikinci bölümde literatür incelemesi gerçekleştirilmiştir. Yöntem kısmında çalışmanın nasıl gerçekleştirildiği açıklanarak hemen ardından aynı bölümde çalışmada kullanılan çok nitelikli fayda teorisi ile birlikte CRITIC ağırlıklandırma yöntemi literatürde kullanılan örnekleri ile beraber adımlarına değinilerek açıklanmıştır. Piyasada en çok satılan beş akıllı saat markası üzerinde gerçekleştirilen uygulama ile birlikte dördüncü bölüm tamamlanarak, elde edilen uygulama sonuçlarının değerlendirildiği ve çalışmanın detaylı yorumlarının sunulduğu sonuç bölümü ile de çalışma sonlandırılmıştır.

\section{Literatür İncelemesi}

Karar teorisi incelendiğinde son yıllarda özellikle iki ana akım üzerinde durulduğu görülmektedir. Bu akımlardan ilki problemleri matematiksel modeller aracılı̆̆ ile modelleyip çözen çok amaçlı karar verme teknikleri iken bir diğeri de alternatifler arasından temel matematik tekniklerini kullanarak seçim yapabilen çok kriterli karar verme teknikleridir.

Çok yaygın bir biçimde kullanılan çok kriterli karar verme tekniklerinin kalitesi de önemlidir. Problem türüne göre hangi tekniğin kullanılmasının daha iyi olacağ şeklinde bir tespit yoktur. Ancak verilerin türüne göre kullanılması gereken teknikler deterministik ya da bulanık olarak belirlenebilmektedir. Sıralama, tercih, sınıflama gibi işlemleri gerçekleştiren bu teknikler yöneylem araştırması konuları içerisinde fazlaca itibara sahip 
tekniklerdir. 1896 yılında pareto üstünlügü kavramı ile temelleri atılan bu tekniklerin gerçekleştirdikleri kesikli matematiksel işlemlerde kriterlerin göreceli önem bilgisine ihtiyaç duymaktadırlar. Zardari ve arkadaşlarına (2014) göre, sonuçları değiştirebilecek nitelikte olan kriter ağırlıklandırma metodları içsel ve dışsal metodlar olarak ikiye ayrılırken, Wang ve arkadaşlarına (2009) göre ise nesnel, öznel ve karma metodlar şeklinde sınıflandırılmaktadır. Nesnel ağırlıklandırma yöntemleri çalışmanın daha güvenilir sonuçlar sunabilmesi açısından ayrıca önem taşımaktadır. Literatürde bahsi geçen bu tekniklerden ilki Entropi yöntemidir. Sonrasında ise düşey ve yatay yöntem, varyasyon yöntemi, çoklu korelasyon yöntemi, temel bileşenler analizi, çok amaçlı optimizasyon yöntemleri, Linmap ve çalışmaya da konu olan CRITIC yöntemi gelmektedir.

CRITIC yönteminin uygulandığı çalışmalarda genellikle hibrit bir yapı yani diğer tekniklerle işbirliği görülmektedir. İlgili literatür incelendiğinde CRITIC yöntemi ile ilgili ilk yayının 1995 yılında Diakolulaki ve arkadaşları tarafından yazılan ve yöntemin ilk anlatıldığı makale olduğu görülmektedir. Bu yöntemin ortaya çıkış sebebi ağırlıklandırma konusunda objektif bir değerlendirme yapılmasıdır. Bu ilk çalışma ile yöntem anlatılmış ve ilaç firmalarının performansının ölçümüne yönelik bir problem üzerine de uygulama yapılarak yöntemin adımları tek tek açıklanmıştır. Daha sonraki yıllarda ise CRITIC ağırlıklandırma yönteminin diğer ağırlıklandırma yöntemleri ile birlikte kullanıldığı, karşılaştırmaların yapıldığı çalışmalar ardı sıra yapılmıştır. Bu çalışmalardan ilki Deng ve arkadaşlarının 2000 yılında gerçekleştirdiği çalışmadır ki dönüştürülmüş TOPSIS yöntemiyle 4 önemli finansal gösterge kriter olarak kullanılmış ve şirketler arası finansal performans karşılaştırmaları yapılmıştır. Bu aşamada sıralama sonucuna etki eden kriterlere ait ağırlıklar dört farklı objektif ağırlıklandırma yönteminden yararlanılarak hesaplanmıştır. Entropi, eşit ağırlık, standart sapma ve CRITIC yöntemleri ile elde edilen ağırlıklar ile TOPSIS' in bütünleşik kullanımı ile elde edilen yedi farklı şirketin sıralamaları arasında inanılmaz farklar tespit edilmemiştir. Ancak probleme en uygun ağırlıklandırma metodunun Entropi olduğu kanısına varılmıştır. Ağırlıklandırma metodlarının karşılaştırıldığı çalışmalardan biri de Yılmaz ve Harmancıoğlu'nun (2010), Gediz Nehri Havzası'nın yönetim alternatiflerine ait performanslarının ekonomik, sosyal ve çevresel sürdürülebilirlik açıklayıcıları 
olan 9 farklı gösterge ile değerlendirildiği çalışmadır. Çok kriterli karar verme tekniklerinden basit toplam ağırlık (SWA), uzlaşık programlama $(\mathrm{CP})$ ve TOPSIS ile birlikte objektif ağırlıklandırma metodlarından Entropi, CRITIC, Standart Sapma ve Eşit Ağırlık yöntemi kullanılarak göstergelerin ağırlıklandırılması ve yöntemle birlikte değişen alternatiflerin sıralama sonuçlarının karşılaştırılması gerçekleştirilmiştir. Objektif ağırlandırma ile gerçekleştirilen tüm çok kriterli karar verme tekniklerinin sonuçları aynı tespit edilmiştir. Subjektif ağırlıklandırma ile elde edilen sonuç ise farklılık arz etmektedir. Alemi-Ardakani ve arkadaşlarına (2016) ait çalışmada ise Entropi, Modifiye Edilmiş Dijital Mantık, CRITIC yöntem gibi objektif yöntemlerin yanında Sayısal Mantık ve Ayarlanabilir Ortalama Çubuk gibi yeni ağırlıklandırma yöntemlerini de hesaba katarak çok kriterli karar verme teknikleri üzerindeki etkilerini araştırmak ve optimum dokuma desen seçimi problemi üzerinde bir uygulama gerçekleştirmek istemişlerdir. Sonuçta kombinasyon olarak kullanılan metotların karar vermede daha etkili olduğu sonucuna ulaşılmıştır.

CRITIC yöntemi ağırlıklandırma söz konusu olabilecek tüm problemlerde kullanılabilmektedir. Örneğin firmaların performans ölçümündeki finansal oranların ağırlıklandırılmasında sıklıkla kullanıldığı görülmüştür. Çakır ve Perçin (2013), 10 farklı lojistik firmasının 6 farklı finansal oranı kriter olarak kullanarak finansal performans değerlendirilmesi yapılmıştır. İlk aşamada CRITIC yöntemi ile kriterlerin göreceli önemleri hesaplanmış sonrasında ise SAW (Basit Toplamlı Ağırlıklıklandırma), TOPSIS ve VIKOR yöntemleri ile firmalar arası sıralama elde edilmiştir. Son olarak da Borda Sayım Yöntemi ile en iyi sıralama belirlenmiştir. Kazan ve Özdemir'in 2014 yılında yaptıkları benzer bir çalışmada İstanbul Menkul Kıymetler Borsası'nda işlem gören 4 büyük holdingin finansal performansı 19 finansal oran ile hesaplanmıştır. Holdinglere özgü finansal oranların kendi içerisinde değişen önemleri için CRITIC yöntem kullanılmış ve TOPSIS ile en iyi finansal performansa sahip holding saptanmıştır. Ünlü ve arkadaşları (2017), Borsa İstanbul 30 endeksinde yer alan firmalardan kurumsal yönetim endeksinde yer alan ve almayan firmalara dair finansal performans ölçümü gerçekleştirmiştir. Geleneksel ve değere dayalı ölçümlerle belirlenen kriterler CRITIC yöntemi ile ağırlıklandırılmış ve TOPSIS yöntemiyle gerçekleştirilen nihai sıralamada kurumsal yönetim endeksinde yer alan 10 firma ile yer almayan 12 firma 
arasında finansal performansları arasında bir fark saptanmamıştır. Yalçın ve Ünlü (2018), şirketlerin halka arz edilmeden önceki ve sonraki performanslarının ölçüldüğ ü çalışmada, iki bütünleşik yöntemden yararlanmıştır. CRITIC-VIKOR ve Ortalama Ağırlıklı VIKOR yöntemlerinin ölçümü sonucu halka arz edilmiş firmaların muhasebe bazlı, değer bazlı ve genel olarak performans değerlendirilmesi gerçekleştirilmiştir. Ortaya çıkan sonuç hissedarlara yönelik yatırım kararlarına yardımcı olmak adına sunulmuştur.

Madic ve Radovanovic (2015) ise çalışmalarında bir imalat şirketinin başarısı ve rekabetçiliği için kritik öneme sahip geleneksel olmayan işleme sürecinden (lazer ışınla kesme, plazma ark kesime, aşındırıcı su jeti ile kesme, oksiyakıtla kesme) en iyisinin seçimini gerçekleştirmek amacıyla belirlenen 9 farklı tekno-ekonomik kriterin CRITIC yöntem ile önem düzeyleri belirlenmiş ve sonrasında ise Değer Aralığı yöntemi ile en iyi işleme süreci belirlenmiştir.

Bölgesel farklılık analizi ile ilgili bir başka çalışmada Minarcikova (2016) tarafından gerçekleştirilen çalışmadır. Bu çalışmada $A B^{\prime}$ 'ne ait bölgesel istatistik ikinci seviyesinde yer alan Çek Cumhuriyeti, Macaristan, Polonya ve Slovakya'nın ekonomik, sosyal ve bölgesel farklılıklar anlamında yarattığı boyutlardan altı farklı oran saptanmış ve bu oranların hem CRITIC hem de Entropi yöntemi ile önem düzeyleri tespit edilerek TOPSIS yöntemi ile bölge sıralaması gerçekleştirilmiştir. Bu çalışmanın iki amaca hizmet ettiği görülmektedir. İlki TOPSIS ile elde edilen bölgeler arası sıralamanın yarattığı sonuç, ikincisi de ağırlıklandırma yöntemlerinin sonuç üzerinde yarattı̆g 1 etkidir. Bu noktadan hareketle CRITIC yöntemin Entropi yöntemine göre kriterler arası çatışmaları göz önünde bulundurduğu gerekçesi ile daha avantajlı olduğu saptaması yapılmıştır.

Ulusal yazında da Orakçı ve Özdemir (2017) Türkiye ve AB ülkelerinin insani gelişmişlik düzeylerinin ölçümünü gerçekleştirebilmek için eğitim, sağlık ve refah düzeyi ana başlı̆̆ı altında İnsani Gelişmişlik Endeksi'nden ve Avrupa Yaşam Kalitesi anketinden yola çıkarak önem düzeyleri tespit edilecek kriterler belirlenmiştir. Gri İlişkisel Analiz ve MOORA ile ile CRITIC ve Entropi yöntemleri bütünleşik kullanılmış ve gelişmişlik sıralamasına ulaşılmıştır. 
Kılıç ve Çerçioğlu'nun 2016 yılında yatırım kararı ile ilgili yaptıkları çalışmada Devlet Demir Yolları'nın yük taşıma kapasitesi yüksek olan 78 demir yolu bağlantı noktaları arasında bir öncelik sıralama yapmışlardır. Demiryolu bağlantı noktaları ile ilgili tespit edilen kriterler ile ilgili önceliklendirme işlemi CRITIC, Standart Sapma ve Ortalama Ağırlık gibi nesnel ağırlıklandırma yöntemleri kullanılarak gerçekleştirilmiştir. TOPSIS ve VIKOR ile bütünleşik gerçekleştirilen değerlendirme sonucu ortaya sunulan sıralamaların Borda Sayım Yöntemi kullanılarak birleşik sıralamaya ulaşılmıştır.

Ghorabaee ve arkadaşları (2018), inşaat malzemelerinin çevreye yaratabileceği olumsuz etkilerin aza indirilebilmesi için sürdürülebilir inşaat malzemesi seçimi gerçekleştirecek bir çalışma yapmışlardır. Bulanık SWARA ve CRITIC yöntemleri kullanılarak belirlenen kriterlerin subjektif ve objektif ağırlıklandırılması yapılmış ve Bulanık EDAS kullanılarak nihai seçime ulaşılmıştır.

Yarlıkaş (2018) farklı bir çalışma ile CRITIC - MOOSRA teknikleri ile Türkiye Basketbol Süper Liginde yer alan takımların lig boyu gösterdikleri performansların değerlendirmesini yapmış, belirlenen 8 farklı teknik değişkenin CRITIC ile ağırlıkları belirlenmiş ve MOOSRA ile takım sıralaması elde edilmiştir. Sezon sonunda ortaya çıkan sıralama ile tekniklerin kullanımı ile tespit edilen sıralama karşılaştırması yapılmıştır.

Demircioğlu ve Coşkun (2018), tüketicilere elektrik kesintilerini önleyen güç kaynağı seçimine yardımcı olabilmek adına piyasada bulunan 8 farklı güç kaynağı arasından en iyisini belirleyebilmek için CRITIC-MOOSRA bütünleşik kullanımına başvurmuşlardır. Güç kaynaklarına özgü nicel kriterlere uygulanan CRITIC yöntemi ile birlikte uygulanan karar tekniğinin sıralama sonucu da objektif olarak tespit edilmiştir.

Kiracı ve Bakır (2019), havayolu şirketlerinin performanslarını inceledikleri çalışmada 13 havayolunun 2005-2012 yılları arasındaki önemli 5 kritere ait verileri kullanarak ki bu kriterler nicel ve havayolu şirketlerine özgü performansının ölçümünü gösteren kriterlerdir. CRITIC yöntemi ile önem düzeyleri hesaplanan kriterler, yeni bir karar tekniği olan EDAS yöntemi ile küresel finans krizi ve öncesi 13 havayolu şirketinin kıyaslaması yapılmıştır. Finansal krizin en çok hissedildiği yıl olarak 2010 yilı bulunmuştur. 
Alternatiflerin seçimine gelindiğinde ise literatürde pek çok sıralama ve seçim yapan teknik bulunmaktadır. Bunlardan en önemlileri TOPSIS, VIKOR, ANP, AHP, PROMETHEE, ELECTRE, MOORA, MOOSRA vb. tekniklerdir. Bu tekniklerden arasında çalışmaya konu olan teknik ise alternatifler arasından en çok faydayı elde etmeyi amaçlayan teknik olan kısaltması MAUT olan Çok Nitelikli Fayda Teorisidir. MAUT ilk uygulanan karar tekniklerinden biri olmasına rağmen farklı araştırmacılar tarafından bazı özellikleri daha da geliştirilerek tekrar gündeme gelmiştir. Ekonomi, finans, enerji, tarım, su kaynakları yönetimi gibi alanlarda sıklıkla uygulandığı görülen MAUT, belirsizliği hesaba katma kabiliyeti olması sebebiyle büyük bir güce sahiptir. Bu gücünü yeterli miktarda veri kullanımı ile daha da arttırılabilir.

Kailiponi (2010) çalışmasında tahliye kararlarının alınmasını kolaylaştıran problemlerde acil durum yöneticilerine yardım etmek amacıyla MAUT yöntemini kullanmış ve Avrupa Komisyon projelerinden toplanan verilerle herhangi bir fırtına durumunda tahliye senaryolarını yönetebilmek için Avrupa'nın sekiz farklı ülkesinin acil durum yöneticilerinin ortaklaşa belirledikleri kriterler kullanılmıştır. MAUT yönteminin modellediği senaryolarda tahliye kararlarının analiz edilerek farklı eğitim senaryolarına ağırlık verilmesi önerisinde bulunulmuştur.

Tedarikçi seçimi ile ilgili problemlerde de kullanılan MAUT, Freitas ve arkadaşlarının 2013 yılında gerçekleştirdikleri çalışmada da bu alanda kullanılmıştır. Metalürji sektöründe işler yapan bir firmanın hammadde ihtiyacını karşılamak adına üç farklı hammadde tedarikçisi arasından en iyi firmanın seçimi konusundaki problemine öncelikle istenen kriterler belirlenerek başlanmıştır. Daha sonra ise bu kriterler hem MAUT hem de Analitik Hiyerarşi Prosesi (AHP) yöntemleri kullanılarak karşılaştırılmıştır. Her iki teknikle de elde edilen sonuç aynı hammadde tedarikçisini göstermiştir.

Ahmed ve Lam (2014), küçük çapta bir ilaç firması için malzeme taşıma ekipmanının seçimi ile ilgili öneride bulundukları çalışmalarında birbiriyle çelişen amaçların varlığ 1 ve uygun görünen pek çok alternatif arasından seçim yapılması gerekliliği sebebiyle MAUT yöntemine başvurarak dört alternatif değerlendirmesi yapmışlardır. Üç ana kriter ve hiyerarşik olarak alt kriterlerin de ele alındığı çalışmada karar vericinin tercih ettiği 
tek noktadan tahmin ile ilgili belirsizliği yakalamak için Monte Carlo Simulasyonuna başvurulmuştur. Bitmiş ürün envanteri için iyi bir model kurulduğu karar vericilerin yargıları ile netleştirilmiştir.

Petrol ve gaz endüstrisindeki faaliyetler riski yüksek faaliyetler olmakla birlikte Lopes ve Almeida (2015) çalışmalarında riski oluşturan faktörleri de dikkate alarak petrol ve gaz arama çalışmalarında oluşan projelere yönelik değerlendirmelerde bulunmuşlardır. Çalışmanın en önemli amacı bu konuda proje seçiminin yanında aslında portföy projesi seçimidir. Bu noktada MAUT yöntemine başvurulmuş ve hem modeli tartışmak hem de görselleştirebilmek için sayısal uygulama gerçekleştirilmiştir. Proje karar vericinin tercih yapısına bağlı kalınarak sonuçlar netleştirilmiştir.

Ömürbek ve arkadaşlarına (2016) ait çalışmada Borsa İstanbul'da işlem gören otomotiv firmalarının finansal performanslarının sadece muhasebe bazlı oranlarla ölçümünün gerçekleştirilmesi değil, ayrıca bu oranları da kullanarak otomotiv firmalarının kendi aralarındaki performans sıralamalarının gerçekleştirilmesi de mümkün olmuştur. Çalışma firmaların 2014 yılına ait nicel verilerine sahip olması sebebiyle, nicel verilere nesnel bir değerlendirme yapmak istemiş ve Entropi ağırlıklandırma yöntemi ile kriterlerin önem düzeylerini belirlemiştir. Sonraki aşamada ise MAUT ve SAW yöntemlerini kullanarak sıralama gerçekleştirmişler. İki teknik karşılaştırıldığında sıralamanın birinci, ikinci ve üçüncü firmalarının aynı olduğu saptanmıştır.

Organ ve Kenger (2017), Hatay ili sınırları içerisinde faaliyet gösteren bir bankanın personel seçimi ile ilgili problemini çözmek için başvuran 5 aday arasından en iyiyi seçmek amacıyla bu çalışmayı gerçekleştirmişlerdir. 10 önemli özellik kriter olarak değerlendirmeye alınmış ve Entropi yöntemi ile ağırlıklandırılmış ve önce MAUT, sonra Gri İlişkisel Analizi yöntemi ile adayların sıralaması gerçekleştirilmiştir. Ortaya çıan sonuca göre, iki teknik farklı kişilerin işe alınması konusunda öneride bulunmuş ve seçimi bankaya bırakmıştır.

Kaplanoğlu (2019), Makine ve Kimya Endüstrisi Kurumuna bağlı on adet fabrikanın finansal ve finansal olmayan kriterler bazında ayrı ayrı değerlendirilmesi ile performans karşılaştırılması yapılmak istenmiştir. 2015 ve 2016 yıllarına ait 7 finansal oran kriter olarak (net Kâr/net Satışlar, stok büyüme hızı, satışların büyüme hızı, üretim büyüme hızı, harcama 
büyüme hızı, net satışlar/çalışan sayısı, çalışan başına kâr/zarar) kullanılmıştır. Entropi yöntemi ile kriterler arası önem düzeyleri hesaplanarak MAUT ile hem 2015 hem de 2016 yılları için aynı kuruma bağlı on adet fabrikanın sıralaması ortaya konulmuştur. Yıllar arası sıralama sonucunun değişim göstermediği tespit edilmiştir.

Yukarıda görüldüğü üzere CRITIC ağırlıklandırma yöntemi ve MAUT ile ilgili ayrı ayrı pek çok ulusal ve uluslar arası yazın bulunmaktadır. İki yöntemin bir arada bulunduğu çalışmalar çok azdır. Bu çalışmalardan biri 2017 yılında Adalı ve Işık tarafından yapılmış bir çalışmadır. Şirketlerin rekabetçi pazarda bir konum oluşturabilmek ve müşteri gereksinimlerine etkin ve hızlı bir şekilde cevap verebilmesi problemi üzerinde durulan çalışmada amaç bazı imalat işlemlerinin taşeron kullanılarak gerçekleştirilmesidir. Fason üretim ile operasyonel maliyetlerin düşürülmesi, karın artırılması ve üretim kabiliyetinin esnek bir şekilde yapılması amaçlanmaktadır. Bu nedenle taşeron üreticinin seçimi önem kazanmıştır. Seçim için kullanılacak kantitatif ve kalitatif kriterler CRITIC yöntem kullanılarak ağırlıklandırılmış ve MAUT ile taşeron üreticilere ait değerlendirmeler yapıldıktan sonra ulaşılan sıralamadan en iyi taşeron firmanın seçimi gerçekleştirilmiştir.

Literatür genel olarak tarandığında CRITIC ve MAUT ile farklı farklı tekniklerin bir arada kullanıldığı pek çok çalışmanın varlığı tespit edilmiştir. Ancak bütünleşik kullanımına pek sık rastlanmamıştır. Bu nedenle bu çalışmada CRITIC ve MAUT tekniklerinin bütünleşik kullanımı ile farklı bir uygulama gerçekleştirilmek istenmiştir.

\section{Yöntem}

Yöntem bölümü iki aşamadan oluşmaktadır. İlkinde tercihlerin kolaylaşmasını sağlamak amacıyla belirlenen kriterlerin önem düzeylerinin tespitinde kullanılan CRITIC yönteminin nasıl gerçekleştirildiği ortaya konmuştur. İkinci aşamada ise araştırmaya konu olan alternatiflerin faydasını ölçen MAUT yönteminin adımları açıklanmıştır. 


\section{Çok Nitelikli Fayda Teorisi (MAUT)}

Çok nitelikli karar verme yöntemlerinin bir parçası olan MAUT (MultiAttribute Utility Theory) yönteminin teorik alt yapısı Keeney ve Raiffa tarafından 1976 yılında yazılmıştır. Ancak farklılaşan çalışmalar ile daha da geliştirilen teknik ana amacını maksimize edilmesi gereken gerçek hayat problemleri için en çok faydayı sağlama fikri üzerine kurmasıyla son halini almıştır. Wang ve arkadaşlarına göre (2010), MAUT yöntemi tüm alternatifleri eş zamanlı olarak karşılaştırması ile en faydalı alternatife yönelme konusunda farklılık sunmaktadır. Karar vericiler için basit ve sezgisel bir teknik olan MAUT için farklı kriterlere farklı ağırlık dağılımı yapılması önem taşımaktadır (Zietsman vd., 2006, s. 255). Pek çok alana uygulanan yöntemin farklı çalışmalar ile zenginleşen adımları aşağıda sunulduğu gibidir.

- Adım 1. Probleme konu olan kriterler, varsa alt kriterler ve alternatifler tanımlanır ve belirlenir.

- Adım 2. Kriterler nicel ve nitel olup olmadıklarına göre değerlendirilir. Nicel değer ölçüleri, kendi değerleri ile karar matrisinde yerini alırken, nitel değer ölçüleri için önce bir atama gerçekleştirilir. Bu atamalar ikili karşılaştırmalar göz önünde bulunarak yapılan ve 5'lik, 100'lük şeklinde gerçekleştirilen atamalardır. Bu işlemin sonucunda nitel kriterlere ait değerler karar matrisine yerleştirilmektedir.

- Adım 3. Kriterlerin doğru bir şekilde değerlendirilmesi için göreceli önem değerleri hesaplanır. Farklı kriter ağırlıklandırma teknikleri kullanarak hesaplanan değerler bu aşamada kullanılabilir. Tüm kriterlere ait göreceli önem değerlerinin toplamının bire eşit olması temel kuraldır.

$$
\sum_{1}^{m} w_{i}=1
$$

- Adım 4. Karar matrisi X, farklı alternatiflere karşlık gelen çeşitli kriter değerlerini göstermektedir.

$$
X=\left[X_{i j}\right]_{m x n}=\left[\begin{array}{ccc}
x_{11} & \cdots & x_{1 n} \\
\vdots & \ddots & \vdots \\
x_{m 1} & \cdots & x_{m n}
\end{array}\right](\mathrm{i}=1,2 \ldots, \mathrm{m}) \text { ve }(j=1,2 \ldots \ldots n)
$$


$X_{i j}$ i. alternatifin j. kriter üzerindeki değerini ifade etmektedir.

- Adım 5. Her bir kriter için fayda fonksiyonunun hesaplandığ1 adımdır. Normalizasyon işlemi ile en iyi ve en kötü değerler belirlenip, en yüksek memnuniyet seviyesine 1, en kötü seviyeye ise 0 değeri atanır. Bu değerler dışında kalan değerler içinse aşağıda verilen normalizasyon formülü kullanılır (Freitas vd., 2013, s.96). Eşitlik 3 ve 4 ile sırasıyla fayda ve maliyet yönlü kriterlere ait normalizasyon işlemi yapılabilir.

$$
\begin{aligned}
& u_{j}\left(x_{i j}\right)=\frac{x_{i j}-\min \left(x_{i j}\right)}{\operatorname{maks}\left(x_{i j}\right)-\min \left(x_{i j}\right)}(i=1,2 \ldots, m) \text { ve }(j=1,2 \ldots \ldots, n) \\
& u_{j}\left(x_{i j}\right)=\frac{\operatorname{maks}\left(x_{i j}\right)-x_{i j}}{\operatorname{maks}\left(x_{i j}\right)-\min \left(x_{i j}\right)}(i=1,2 \ldots, m) \text { ve }(j=1,2 \ldots \ldots, n)
\end{aligned}
$$

$u_{j}\left(x_{i j}\right)$ fayda fonksiyonundan normalize edilen ölçeğe göre belirlenen normalize edilmiş kriter değeridir.

- Adım 6. Normalizasyon işleminin hemen ardından MAUT tekniği için en önemli olan fayda değeri belirleme aşamasına geçilir.

$$
U\left(A_{i}\right)=\sum_{j=1}^{n} w_{j} u_{j}\left(x_{i j}\right)
$$

$U\left(A_{i}\right)$ i. alternatifin fayda değerini gösterirken, $w_{j}$ ise $\mathrm{j}$ kriterine ait göreceli önem değerini göstermektedir. $u_{j}\left(x_{i j}\right)$ ifadesi ise fayda fonksiyonundan elde edilmiş normalize tek bir değerdir. Karar verici ağırlıklandırılmış fayda değerinin en yüksek değerini seçmelidir (Wang vd., 2010, s. 753).

\section{CRITIC (CRiteria Importance Through Intercriteria Correlation) A ̆̆ırlıklandırma Yöntemi}

Açılımı Kriterler Arası Korelasyon Yoluyla Kriterlerin Önem Tespiti şeklinde olan CRITIC yöntemi, bir arada değerlendirilen kriterlerin kendi aralarında göreceli önemlerinin objektif bir şekilde hesaplandığı bir 
ağırlıklandırma yöntemidir. 1995 yılında Diakoulaki ve arkadaşlarının önerdiği teknik, karşıtlı̆ın yoğunluğu ve karar verme problemlerinin yapısındaki uyuşmazlıklara yoğunlaşmaktadır. Korelasyon analizi bu aşamada devreye girmekte ve kriterler arasındaki zıtlıkları ortaya koymaktadır. Karar matrisinde normalleştirilmiş kriter değerlerinin sütunlara göre standart sapması ve tüm sütun çiftlerinin korelasyon katsayıları kullanılmaktadır.

CRITIC yöntemine ait adımlar aşağıda sunulduğu gibidir (Diakoulaki vd.,1995,s.765):

Bir karar probleminde $\mathrm{m}$ adet uygun alternatif kümesi $A_{i}(i=$ $1,2, \ldots, m)$ ve $n$ adet $k$ riter $K_{j}(j=1,2, \ldots, n)$ olduğu varsayımı ile hareket edilerek beş farklı adım izlenir.

- Adım 1. X karar matrisinin düzenlenmesidir. Bu karar matrisi farklı alternatiflere karşıllı gelen kriter değerlerini barındırmaktadır.

$$
X=\left[x_{i j}\right]_{m x n}=\left[\begin{array}{ccc}
x_{11} & \cdots & x_{1 n} \\
\vdots & \ddots & \vdots \\
x_{m 1} & \cdots & x_{m n}
\end{array}\right]
$$

$$
i=(1, \ldots \ldots, m) \text { ve } j=(1, \ldots \ldots, n)
$$

$x_{i j}, i$. alternatifin $j$. kriter değerini ifade etmektedir.

- Adım 2. Normalizasyon işleminin gerçekleştirildiği bu adımda Eşitlik 7'deki fayda yönlü kriterler için kullanılırken, Eşitlik 8 ise, maliyet yönlü kriterlere ait değerlerin hesaplanmasında kullanılmaktadır.

$$
\begin{aligned}
& x_{i j}{ }^{*}=\frac{x_{i j}-\min \left(x_{i j}\right)}{\operatorname{maks}\left(x_{i j}\right)-\min \left(x_{i j}\right)} \quad i=(1, \ldots \ldots, m) \text { ve } j=(1, \ldots \ldots, n) \\
& x_{i j}{ }^{*}=\frac{\operatorname{maks}\left(x_{i j}\right)-x_{i j}}{\operatorname{maks}\left(x_{i j}\right)-\min \left(x_{i j}\right)} \quad i=(1, \ldots \ldots, m) \text { ve } j=(1, \ldots \ldots, n) \\
& x_{i j}{ }^{*} \text { normalize edilmiş kriter değeridir. }
\end{aligned}
$$


- Adım 3. Kriterler arasındaki ilişkinin gücünü ortaya koyabilmek adına kriter çiftleri arasındaki korelasyonun katsayıları bu adımda hesaplanır. Burada en önemli nokta normalize edilen karar matrisindeki kriterlere ait değerlerin normal dağılıma sahip olup olmadığıdır. Bu noktada devreye normal dağılım testleri devreye girmektedir. Normal dağglım test sonucuna göre eğer veriler normal dağglıyorsa Eşitlik 9'da görülen Pearson korelasyon katsayısı formülü kullanılmalıdır.

$$
p_{j k}=\frac{\sum_{i=1}^{m}\left(x_{i j}{ }^{*}-\bar{x}_{j}\right)\left(x_{i k}-\bar{x}_{k}\right)}{\sqrt{\sum_{i=1}^{m}\left(x_{i j}{ }^{*}-\bar{x}_{j}\right)^{2} \sum_{i=1}^{m}\left(x_{i k}-\bar{x}_{k}\right)^{2}}}
$$

Veriler arasında normal dağılım söz konusu değilse Spearman sıra korelasyon katsayısı formülü ile kriterler arası ikili korelasyon katsayısı hesaplanabilir (Kiracı ve Bakır, 2019, s. 166).

$$
p_{j k}=1-\frac{6 * \sum_{i=1}^{m} d^{2}}{n *\left(n^{2}-1\right)}
$$

$\mathrm{d}$ ifadesi iki kriterin sıralamaları arasındaki farkı gösterirken, $\mathrm{n}$ ise kriter büyüklüğüdür.

- Adım 4. Her bir kriterde bulunan toplam bilginin hesaplandığ aşamadır. $C_{j}$ bilgi miktarı, normalize edilmiş karar matrisinin sütun değerlerinin standart sapması $\left(\sigma_{j}\right)$ da kullanılarak hesaplanmaktadır.

$$
C_{j}=\sigma_{j} \sum_{k=1}^{n} 1-p_{j k}
$$


Madic ve Radovanovic (2015)'e göre standart sapma değeri yüksek ve buna karşılık korelasyon katsayı değerleri düşük olarak tespit edilen kriterler yüksek $C_{j}$ değerine sahip ve en yüksek öneme sahip kriterlerdir.

- Adım 5. Tüm kriterlerin sahip oldukları bilgilerin hesabı gerçekleştirildikten sonra son adım olan bu adımda kriterlere ait nesnel ağırlıklar $W_{j}$ hesaplanır.

$$
w_{j}=\frac{c_{j}}{\sum_{k=1}^{n} c_{k}}
$$

Eşitlik 12' de de görüldüğü üzere en yüksek değerden en düşük değere kadar kriterlerin ağırlıklarının sıralaması gerçekleştirildiğinde ortaya çıkan en yüksek ağırlığa sahip kriterin daha önemli olduğudur.

\section{Akıllı Teknolojik Saatlerin Tercihi Üzerine Bir Uygulama}

Akıllı telefonların seçimi konusunda dikkate alınması gereken kriterlerin belirlendiği ve göreceli önemlerinin ortaya konulduğu çalışmalarda 2012 yılından beri görülen artış akıllı telefon kullanımının artması ile doğru orantılıdır. Bu nedenle özellikle seçim kriterlerinin doğru belirlenmesi ve alternatiflerin arasından en çok fayda sağlayanın seçimi önem kazanmıştır. Bu çalışmada da akıllı telefonların teknolojik bütünlügünü sağlayan akıllı saatlerle ilgili bir araştırma yapılmış ve en çok faydayı sağlayan teknolojik saatin tespiti konusunda fayda konusu üzerinde daha da önemle duran çok nitelikli fayda teorisi yaklaşımı tercih edilmiştir.

Literatürde akıllı saatlerin tercihine yönelik bir çalışmaya rastlanmamış olması teknoloji ile uyumlu bu saatlerin henüz yeni yeni piyasada dikkat çeken ürünler olması ile ilgili olduğu düşünülmektedir. O nedenle bu çalışmada akıllı saat tercihini kolaylaştıracak kriterler ile akıllı telefonların tercih değerlendirmesinde istenen kriterlerin benzerlikler taşıması kaçınılmaz olmuştur. Kriterlerin belirlenmesinde ulusal ve uluslararası yazındaki pek çok çalışmadan yararlanılmıştır. Bu çalışmalara örnek olarak $\mathrm{Hu}$ ve Liao (2013), Çakır ve Demir (2014), Konuşkan ve Uygun'un (2014), Büyüközkan ve Güleryüz (2016), Şahin ve Aydemir (2019), Perçin ve Pancaroğlu'na (2019) ait çalışmalar verilebilir. Akıllı teknolojilere yönelik genel olarak akıllı telefonların çeşitli özelliklerinin ortaya konulduğu, tercih 
edilme nedenlerinin belirlendiği ve satın alma kararına etki eden faktörlerin sıralandığı tüm bu çalışmalar gözden geçirilerek benzer bir teknoloji olan akıllı saatlerin tercih edilmesine yönelik önemli görülen tüm kriterler belirlenmiştir. Sonrasında ise çalışmaya uygun olacak şekilde saptanan nicel ve nitel kriterler ile hepsiburada.com ve gittigidiyor.com alışveriş sitelerinde Mayıs 2019 satış verilerine göre en iyi satış rakamına sahip ilk beş akıllı saat teknolojisi sunan firmalar aralarında en iyi olanının belirlenmesi amacıyla değerlendirmeye tabi tutulmuştur. Bu akıllı saat markaları Samsung Galaxy Gear S3 Frontier, Huawei Watch GT Sport, Xiaomi Amazfit Verge, Apple Watch Seri 4 ve Fitbit Versa şeklindedir. Müşterilerin tercihini etkileyecek kriterler Tablo 1'de sunulduğu gibidir.

\section{Tablo 1. Akıllı Saat Teknolojilerinin Seçimini Etkileyen Kriterler}

\begin{tabular}{clc}
\hline Kriter Kodu & Kriterin Adı & Kriterin Yönü \\
\hline K1 & Pil Ömrü (Miliamper Saat) & Fayda \\
K2 & Ekran Boyutu (İnç) & Fayda \\
K3 & Depolama Alanı (MB, GB) & Fayda \\
K4 & Fiyat (TL) & Maliyet \\
K5 & Ağırlı (Gram) & Maliyet \\
K6 & Kullanım Kolaylı̆̆ı & Fayda \\
K7 & Tasarım Çeşitliliği & Fayda \\
K8 & Satış Sonrası Hizmetler & Fayda \\
K9 & Marka İmajı & Fayda \\
K10 & Sağlamlık & Fayda \\
K11 & Estetik Görünüm & Fayda \\
K12 & Sağlıkla İlgili Uygulamaların Varlığı & Fayda \\
\hline
\end{tabular}

Yukarıda sunulan kriterlerin göreceli önem düzeylerinin tespit edildiğ $i$ anket çalışması, akıllı teknolojik ürünlerin satışını yapan sektörün öncü firmalarında çalışmakta ve 10 yıl üzeri satış tecrübesine sahip yedi satış uzmanı ile gerçekleştirilmiştir. Objektif bir önem düzeyi belirleme yöntemi olan CRITIC ağırlıklandırma yöntemi, hem nicel kriter değerlerini hem de MAUT ile nicel değerleri hesaplanmış olan nitel kriterleri kullanarak hesaplama adımlarını tamamlamıştır. En iyi akıllı saat markasını belirleme aşamasında ise maliyet ve fayda yönleri ile de tıpkı önem düzeylerinde olduğu gibi birbirinden ayrlan kriterler nezdinde MAUT yöntem aşamaları izlenerek nihai seçim kararı için bir fikir önerisine ulaşılmiştır.

\section{Bulgular ve Yorum}


Meydana gelen karar probleminin çözümü konusunda ihtiyaç duyulan ilk önce kriterlerin ve alternatiflerin bir arada gösterildiği karar matrisidir. Buna göre, 5 farklı alternatife ait 12 kriterin birlikte gösterildiği karar matrisinin oluşturulması gerekmektedir. Kriterler içinden K1- K5 kriterleri akıllı saatlere ait nicel değerleri gösterirken, direkt olarak karar matrisine yazılmıştır ancak K6- K12 kriterleri nitel veriler olduğu için MAUT yönteminin ikinci adımında belirtildiği şekilde konusunda uzman 7 satış elemanı ile görüşülerek nicel değerlere dönüşüm gerçekleştirilmiştir. Uzmanlar 1'den 5'e kadar puanlar vererek alternatif bazında kriterleri kendi aralarında değerlendirmişlerdir. Toplanan puanlar nitel verilerin nicel verilere dönüştürülmesindeki kilit noktadır. Kilit işlemin ardından karar vericilerin gerçekleştirdikleri değerlendirmenin ortalaması alınarak karar matrisine nicel değerler olarak eklenmiştir. Tablo 2'de karar matrisinde tüm veriler nicel değerler olarak yer almaktadır.

Tablo 2. Karar Matrisi

\begin{tabular}{ccccccccccccc}
\hline & K1 & K2 & K3 & K4 & K5 & K6 & K7 & K8 & K9 & K10 & K11 & K12 \\
\cline { 2 - 12 } A1 & 380 & 1.3 & 4096 & 1249.9 & 63 & 4.14 & 3.86 & 3.86 & 4.43 & 4.14 & 4.14 & 4.57 \\
A2 & 420 & 1.39 & 128 & 965 & 46 & 3.86 & 4.29 & 5.00 & 4.57 & 4.57 & 4.71 & 5 \\
A3 & 390 & 1.3 & 4096 & 799 & 46 & 2.71 & 2.86 & 2.71 & 3.29 & 3.86 & 3.57 & 3.29 \\
A4 & 476 & 1.78 & 16384 & 3099 & 48 & 4.43 & 4.29 & 4.14 & 4.43 & 4.71 & 4 & 3.86 \\
A5 & 145 & 1.34 & 4096 & 1699 & 37 & 2 & 1.57 & 1.86 & 1.86 & 2 & 2 & 2.29 \\
\hline
\end{tabular}

CRITIC yöntemi ile kriterlere ait objektif ağırlıklandırmanın gerçekleştirilebilmesi için ikinci adımda karar matrisi normalizasyonu ile kriterlerin yönlerine göre hesaplama yapılmıştır. Bu şekilde Eşitlik 7 kullanılarak elde edilen normalize edilmiş karar matrisi Tablo 3'de sunulduğu gibidir.

Tablo 3. Normalize Edilmiş Karar Matrisi

\begin{tabular}{lllllllllllll}
\hline & K1 & K2 & K3 & K4 & K5 & K6 & K7 & K8 & K9 & K10 & K11 & K12 \\
\hline A1 & 0.7099 & 0 & 0.2441 & 0.8037 & 0 & 0.8824 & 0.8421 & 0.6363 & 0.9473 & 0.7895 & 0.7895 & 0.8421 \\
A2 & 0.8308 & 0.1875 & 0 & 0.9278 & 0.6538 & 0.7647 & 1 & 1 & 1 & 0.9474 & 1 \\
A3 & 0.7402 & 0 & 0.2441 & 1 & 0.6538 & 0.2941 & 0.4737 & 0.2727 & 0.5263 & 0.6842 & 0.5789 & 0.3684 \\
A4 & 1 & 1 & 1 & 0 & 0.5769 & 1 & 1 & 0.7273 & 0.9474 & 1 & 0.7368 & 0.5789 \\
A5 & 0 & 0.0833 & 0.2441 & 0.6087 & 1 & 0 & 0 & 0 & 0 & 0 & 0 & 0 \\
\hline
\end{tabular}

Normalize edilme işlemi tüm kriterlere ait değerlerin standart hale getirilmesi için gerçekleştirilmiştir. Bu noktada bilgi miktarının $\left(C_{j}\right)$ elde 
edilebilmesi için standart sapma değerlerinin hesaplanması gerekmektedir. Bu hesaplamayı yapabilmek için verilerin normal dağılıp dağılmadığına bakılması gerekmektedir. Minitab ile gerçekleştirilen bu işlemde Shapiro-Wilks normallik testi gerçekleştirilmiş ve verilerin normal dağılmadığı tespit edilmiştir. Buna göre veriler için Spearman sıra korelasyon analizinden yararlanılmış ve Tablo 4'de gösterilen katsayılar elde edilmiştir.

Tablo 4. Kriterler arası korelasyon katsayıları

\begin{tabular}{|c|c|c|c|c|c|c|c|c|c|c|c|c|}
\hline & K1 & K2 & K3 & K4 & K5 & K6 & K7 & K8 & K9 & K10 & K11 & K12 \\
\hline K1 & 1.000 & 0.667 & 0.224 & -0.100 & -0.359 & 0.700 & 0.872 & 0.800 & 0.667 & 0.900 & 0.500 & 0.500 \\
\hline K2 & 0.667 & 1.000 & 0.229 & -0.616 & 0.079 & 0.410 & 0.632 & 0.564 & 0.395 & 0.667 & 0.205 & 0.205 \\
\hline K3 & 0.224 & 0.229 & 1.000 & -0.671 & -0.344 & 0.447 & 0.000 & -0.224 & -0.344 & 0.224 & -0.447 & -0.447 \\
\hline K4 & -0.100 & -0.616 & -0.671 & 1.000 & 0.154 & -0.400 & -0.154 & 0.000 & 0.103 & -0.300 & 0.200 & 0.200 \\
\hline K5 & -0.359 & 0.079 & -0.344 & 0.154 & 1.000 & -0.872 & -0.553 & -0.462 & -0.526 & -0.616 & -0.564 & -0.564 \\
\hline K6 & 0.700 & 0.410 & 0.447 & -0.400 & -0.872 & 1.000 & 0.821 & 0.700 & 0.667 & 0.900 & 0.600 & 0.600 \\
\hline K7 & 0.872 & 0.632 & 0.000 & -0.154 & -0.553 & 0.821 & 1.000 & 0.975 & 0.921 & 0.975 & 0.821 & 0.821 \\
\hline K8 & 0.800 & 0.564 & -0.224 & 0.000 & -0.462 & 0.700 & 0.975 & 1.000 & 0.975 & 0.900 & 0.900 & 0.900 \\
\hline K9 & 0.667 & 0.395 & -0.344 & 0.103 & -0.526 & 0.667 & 0.921 & 0.975 & 1.000 & 0.821 & 0.975 & 0.975 \\
\hline K10 & 0.900 & 0.667 & 0.224 & -0.300 & -0.616 & 0.900 & 0.975 & 0.900 & 0.821 & 1.000 & 0.700 & 0.700 \\
\hline K11 & 0.500 & 0.205 & -0.447 & 0.200 & -0.564 & 0.600 & 0.821 & 0.900 & 0.975 & 0.700 & 1.000 & 1.000 \\
\hline K12 & 0.500 & 0.205 & -0.447 & 0.200 & -0.564 & 0.600 & 0.821 & 0.900 & 0.975 & 0.700 & 1.000 & 1.000 \\
\hline
\end{tabular}

Korelasyon katsayılarının hesabı ile birlikte bilgi miktarının hesaplanması aşamasına gelinmiştir. Kriterlere ait standart sapmalar hesaplanıp adım 4'de yer alan Eşitlik 11 kullanılarak $C_{j}$ değerleri hesaplanmıştır. Buna göre 12 farklı kriterin verdikleri bilgilerle ortaya koydukları ağırlıkları Eşitlik 12 kullanılarak Tablo 5'de sunulduğu gibi hesaplanmıştır.

Tablo 5. Akıllı Saat Teknolojilerinin Seçimini Etkileyen Kriterlerin Ağırlıkları

\begin{tabular}{lllllllllllll}
\hline & K1 & K2 & K3 & K4 & K5 & K6 & K7 & K8 & K9 & K10 & K11 & K12 \\
\hline $\boldsymbol{w}_{j}$ & 0.059 & 0.088 & 0.128 & 0.138 & 0.154 & 0.074 & 0.057 & 0.053 & 0.063 & 0.056 & 0.063 & 0.066 \\
\hline
\end{tabular}

Akıllı saat teknolojisi konusunda görülen o ki en önemli kriter saatin sahip olduğu ağırlık olarak tespit edilmiştir. Genellikle spor yapılırken takıldığ bilinen akıllı saatlere yönelik böyle bir sonuç çıkması şaşırtıcı değildir. Ağırlık kriteri sonrası ikinci sırada önemli görülen tercih kriteri fiyat ve sonrasında ise depolama alanı şeklinde önem düzeyleri ortaya konulmuştur. Sonrasında ise akılı saatin boyutu gelirken, hemen sonraki önemde kriter kullanım kolaylığı gelmektedir. Sağlıkla ilgili uygulamaların varlığı, marka imajı, estetik görünüm, pil ömrü, tasarım çeşitliliğii, sağlamlık ve son sırada ise satış sonrası hizmetler gelmektedir. Tüm bu 
kriterlerin nesnel ağırlıklarının varlığında hangi akıllı saat markasının kullanıcıya faydasının daha yüksek olduğu tespit edilebilmesi için MAUT yönteminin ilk aşamasında Tablo 1'de sunulan karar matrisi kullanılmış ve ikinci adımda aynı normalizasyon işlemleri izlenerek Tablo 3'deki normalize edilmiş matris elde edilmiştir.

Tablo 6. Toplam Fayda Değerlerinin Hesaplanması

\begin{tabular}{|c|c|c|c|c|c|c|c|c|c|c|c|c|c|}
\hline & K1 & K2 & K3 & K4 & K5 & K6 & K7 & K8 & K9 & K10 & K11 & K12 & $\begin{array}{l}\text { Top- } \\
\text { lam } \\
\text { Fayd } \\
\text { a } \\
\end{array}$ \\
\hline A1 & 0.042 & 0.000 & 0.031 & 0.027 & 0.154 & 0.066 & 0.048 & 0.034 & 0.059 & 0.045 & 0.050 & 0.055 & 0.611 \\
\hline A2 & 0.049 & 0.016 & 0.000 & 0.010 & 0.053 & 0.057 & 0.057 & 0.053 & 0.063 & 0.053 & 0.063 & 0.066 & 0.541 \\
\hline A3 & 0.044 & 0.000 & 0.031 & 0.000 & 0.053 & 0.022 & 0.027 & 0.015 & 0.033 & 0.039 & 0.037 & 0.024 & 0.324 \\
\hline A4 & 0.059 & 0.088 & 0.128 & 0.138 & 0.065 & 0.074 & 0.057 & 0.039 & 0.059 & 0.056 & 0.047 & 0.038 & 0.849 \\
\hline A5 & 0.000 & 0.007 & 0.031 & 0.054 & 0.000 & 0.000 & 0.000 & 0.000 & 0.000 & 0.000 & 0.000 & 0.000 & 0.093 \\
\hline
\end{tabular}

Toplam fayda sıralamasına baktığımızda görülen 4 . alternatifin tercih edilmesi durumunda kullanıcıların en çok faydayı elde edecekleridir. Alternatif 4, Apple Watch Seri 4 isimli akıllı saattir. Sonrasında ise tüketicilere önerilen sirasıyla Samsung Galaxy Gear S3 Frontier, Huawei Watch GT Sport, Xiaomi Amazfit Verge ve Fitbit Versa şeklinde tespit edilmiştir.

\section{Sonuç}

Teknolojik gelişmeler akıllı saatlerin kullanımını arttırdığı gibi akıllı olarak adlandırılan diğer teknolojik ürünlere de ilgiyi arttırmıştır. Akıllı saatlere bir bütçe ayrılacaksa, bu bütçeye değecek, tüketiciye fayda sağlayacak bir ürün olması adına yapılan literatür araştırması sonucu belli başlı tercih sebebi olan kriterler belirlenmiştir. Bu kriterler nicel olan pil ömrü, ekran boyutu, depolama alanı, fiyat ve ağırlık gibi kriterler olurken nitel kriterler tasarım çeşitliliği, satış sonrası hizmetler, marka imajı, sağlamlık, estetik görünüm ve sağlıkla ilgili uygulamaların varlığı şeklinde tespit edilmiştir. Değerlendirmeye alınan alternatif akıllı saatlere ait kriter değerlerinin tek bir karar matrisi içinde gösterilebilmesi için nitel kriterlerin nicel kriterlere dönüşümde MAUT yönteminden yararlanılmış ve istenen temel karar matrisi oluşturulmuştur. Bu şekilde kriterlerin nicel hale dönüştürülmesi ve kriterlerin kendi içerisindeki önem düzeylerinin objektif bir ağırlıklandırma yöntemi olan CRITIC ile değerlendirilmesi çalışmanın sonuçlarına olan güveni artıran bir unsur olmuştur. CRITIC 
yöntemi kriter değerlerinin normalitesini incelediği gibi kriterlere ait korelasyon katsayıları kriterlerin taşıdığı bilgi düzeylerinin önemini hesaplaması ile bu çalışmada kullanılmış özellikli bir yöntemdir. Elde edilen önem düzeylerine göre akıllı saat alırken dikkat edilmesi gereken ilk kriter saatin ağırlığı olarak tespit edilmiştir. Sonrasında fiyat ve depolama alanı özellikleri gelmiştir. Bu saatlerin daha çok spor yapan kişiler tarafından sıklıkla kullanıldığı bilindiği için sonuçlar çok da şaşırtıcı değildir.

Türkiye'de satış yapan iki önemli internet sitesinden alınan bilgilere göre en çok satışı gerçekleşen beş farklı akıllı saat, tespit edilen kriterler bazında Türkiye'de faaliyet gösteren elektronik ürünler satan dev bir satış zincirinin bir merkezinde 10 yıl üzerinde satış tecrübesi olan ve bu beş farklı akıllı saatin özelliklerini bilerek satışını yapan karar vericiler tarafından değerlendirilmiştir. Oluşturulan ankete verdikleri cevaplar birleştirilerek çalışmada açıklanan MAUT yöntemi kullanarak nihai karara ulaşılmıştır. Buna göre Apple marka akıllı saat en çok fayda sağlayan alternatif olarak tespit edilmiştir. Sonrasında ise sıralama Samsung, Huawei, Xiaomi Amazfit Verge ve Fitbit Versa şeklinde olmuştur. Elde edilen sonuçlarla markaların dünyadaki pazar payları ve satış rakamlarına bakıldığında ilk sırada yer alan Apple markasının en yüksek pazar payına sahip olduğu görülmektedir. Yine Uluslararası veri şirketi IDC'nin (2019) dünya çapında 2018'in çeyrek rakamlarına baktığında şaşırtıcı şekilde Apple'dan sonra Xiaomi markasının yükselen pazar payı dikkat çekmektedir. Çalışmada son sırada tespit edilen Fitbit akıllı saat markasının Xiaomi'den sonra Huawei ve Samsung akıllı saatlerini geçerek 3. sırada yer alması raporda sunulan şaşırtıcı sonuçlardan biridir. Ancak 2017 yılı rakamlarından 2018'e doğru büyümeye bakıldığında ise Samsung ve Huawei markalarının eskiye göre akıllı saatler alanında kendilerini geliştirmeye başladığı görülmektedir. Türkiye'de de çokça satılan bilindik markaların yanında Xiaomi ve Fitbit markalarının bilinirliğinin düşük olması bu çalışmada da bu markaların son sırada tercih edilmesinin açıklamasıdır.

Kısaca çalışma hem akıllı saatlere yönelik değerlendirmede bulunmak, hem de literatürde pek sık rastlanmayan bir kullanımı ile CRITIC-MAUT bütünleşik kullanımının adımlarını akıllı saatlere yönelik bir uygulama 
üzerinde açıklamayı amaçlamıştır. Gelecekteki çalışmalarda akıllı saatlerin bilinirliğinin ve kullanımının yaygınlaşması ile birlikte hem tüketici hem de üretici odaklı farklı çalışmalar gerçekleştirilebilir. Farklı istatistiki tekniklerle ilk önce bir tüketici analizi yapılarak akıllı saatlerin kullanımına yönelik değerlendirme kriterleri ana ve alt başlıklar halinde belirlenebilir ve çok kriterli karar verme tekniklerinin karar vericiye öneride bulunan diğer teknikleri ile gerçekleştirilen çalışmalar arası kıyas yapilabilir. 


\title{
EXTENDED ABSTRACT
}

\section{Multi-Attribute Utility Theory Integration with CRITIC Method: Smart Technology Preference Example}

\author{
Berna Bulğurcu \\ Çukurova University
}

The number of alternative products has increased in the market of smart technologies which develops and diversifies with Industry 4.0. Firms started to develop smart technological devices and introduce smartwatches or wearable smart glasses compatible with smart phones to create mobility in the market as the market of smart phones reached the point of saturation (Wang, 2015, p. 2542). According to the report published by the International Data Company (IDC) in 2019, the 2018 smart wearable product market share numbers show that Apple and Xiaomi firms are the current pioneers of the market, being followed by Samsung, Huawei and Fitbit firms. It is observed that other producers in the market particularly aim to increase preferability when they are involved in businesses to increase their market share. According to Suki and et al. (2013), the provision of new technologies compatible with smart phones serves to increase diversity in the market and reinforce product and brand preferences in the market.

This study presents and assesses the features that play a role in preferring smartwatches compatible with smart phones. It aims to decide on which feature a consumer should lay stress in choosing one brand over another and, in doing so, provides suggestions on the final selection via the experts of the field familiar with the brands in question. In the solution of this problem, the paper draws on the Multi-Attribute Utility Theory (MAUT) which is in certain respects linked to multi-criteria and multi-purpose decision-making techniques as being a body of techniques which renews and enhances itself through different techniques day by day. It is particularly used in rendering non-quantitative attributes quantitative. By employing the CRITIC, which is short for "Criteria Importance Through Intercriteria Correlation" and a weighting method free from subjective assessments, the study identifies the degrees of significance of the preference properties of smart phones defined based on a 
survey of the literature. In addition to all these, the multi-attribute utility theory comes into play at this point again and, to select the alternative that will yield maximum benefits, it makes the suggestion for the most beneficial alternative by using the relative degrees of significance for the criteria via the CRITIC weighting method. In addition to increasing the use of smartwatches, technological developments also stimulate the interest in other technological products known as smart. In order for it to be a product beneficial to the consumer and worthy of the budget, if there is to be a budget allocation for smartwatches, the criteria which represent the reasons for preference are identified based on a literature review. While these criteria include quantitative battery life, screen size, storage space, price and weight, the qualitative criteria are noted as the diversity of design, after-sale services, brand image, durability, aesthetic appearance, availability of healthcare practices.

The MAUT method is used in the conversion of qualitative criteria into quantitative ones and the desired basic decision matrix is thus formed to show the criteria values of alternative smartwatches under evaluation in a single decision matrix. The fact that the criteria are thus rendered qualitative and each criterion's degree of significance is assessed via the objective weighting method of CRITIC increases the reliability of the findings of the study. The CRITIC is a specialised method used in this study in terms of examining the normality of criterion values, and calculating the correlation coefficients of criteria and the significance of the data levels of criteria Based on the acquired levels of significance, the first criterion that needs to be taken into consideration in buying a smartwatch has been found to be its weight. It is followed by price and storage space. These findings are not that surprising, given that it known that these watches are rather more frequently used by people doing sports. Five different smartwatches, which are the top-sellers according to the data retrieved from two important websites selling online in Turkey, have been assessed by the decision-makers with more than ten years of sale experience at the centre of a giant chain store that sells electronic devices and operates in Turkey based on the established criteria, selling the product with the knowledge of these five different smartwatches. The final decision has been reached by combining the answers to the questionnaire and using the MAUT method explained in the study. Accordingly, Apple smartwatch has been identified as the alternative with the maximum number of benefits. This is followed by Samsung, Huawei, Xiaomi Amazfit and Fitbit Versa. Apple in the first rank is seen to have the biggest market share when looked at the market 
shares and sales figures of the brands in the world together with the findings at hand. Similarly, when looked at the global quarter results of 2018 by the IDC (2019), the increasing market share of Xiaomi after Apple surprisingly attracts attention. The fact that the Fitbit smartwatch, being in the last place in the study, surpasses Huawei and Samsung and comes in the third place is one of the surprising findings presented in the report. However, when looked at the growth numbers between 2017 and 2018, it is seen that Samsung and Huawei brands have begun to improve themselves in the field of smartwatches compared to the past. The fact that Xiaomi and Fitbit brands have a low level of popularity in comparison with the best-selling well-known brands in Turkey also explains the reasons for putting these brands in the last place in this study as well.

In short, the study aims to both make assessments on smartwatches and explain the steps of the CRITIC-MAUT integrated use, an infrequent use of these methods in the literature, through its application to smartwatches. In future research, both consumer- and producer-oriented studies can be carried out with the proliferation of the popularity and use of smartwatches.

\section{Kaynakça / References}

Adalı, E. A. ve Işık, A. T. (2017). Critic and maut methods for the contract manufacturer selection problem. European Journal of Multidisciplinary Studies, 2(5), 93-101.

Ahmet, A. ve Lam, S. S. (2014). Material handling equipment selection using multi-attribute utility theory and monte carlo simulation. Proceedings of the 2014 Industrial and Systems Engineering Research Conference.

Alemi-Ardakini, M., S.Milani, M., Yannacopoulos, S. ve Shokouhi, G. (2016). On the effect of subjective, objective and combinative weighting in multiple criteria decision making: A case study on impact optimization of composites. Expert Systems with Applications, 46, 426-438.

Büyüközkan, G. ve Güleryüz, S. (2016). Multi criteria group decision making approach for smart phone selection using intuitionistic fuzzy TOPSIS. International Journal of Computational Intelligence Systems, 9(4), 709 725.

Çakır, F. ve Demir, N. (2014). Üniversite öğrencilerinin akıllı telefon satın alma tercihlerini belirlemeye yönelik bir araştırma. Dokuz Eylül Üniversitesi İktisadi ve İdari Bilimler Fakültesi Dergisi, 29 (1), 213-243. 
Çakır. S. ve Perçin. S. (2013). Çok kriterli karar verme teknikleriyle lojistik firmalarında performans ölçümü. Ege Akademik Bakış, 13(4), 449-459.

Demircioğlu, M. ve Coşkun, İ.T. (2018). CRITIC-MOOSRA Yöntemi ve ups seçimi üzerine bir uygulama. Çukurova Üniversitesi Sosyal Bilimler Enstitüsü Dergisi, 27(1), 183-195.

Deng. H., Yeh. C. H. ve Willis. R. J. (2000). Inter company comparison using modified TOPSIS with objective weights. Computers $\mathcal{E}$ Operations Research, 27, 963-973.

Diakoulaki, D., Mavrotas, G., ve Papayannakis, L. (1995). Determining objective weights in multiple criteria problems: the CRITIC method. Computers E Operations Research, 22, 763-770.

Freitas, L.V., Freitas, A.P.B.R., Veraszto, E.V., Marins, F.A.S. ve Silva, M.B. (2013). Decision-making with multiple criteria using AHP and MAUT: An industrial application. European International Journal of Science and Technology, 2(9), 93-100.

Ghorabaee. M. K., Amiri. M., Zavadskas. E. K. ve Antucheviciene, J. (2018). A new hybrid fuzzy MCDM approach for evaluation of construction equipment with sustainability considerations. Archives of Civil and Mechanical Engineering, 18, 32-49.

$\mathrm{Hu}$, Yi-Chung ve Liao, Yu-Lin (2013). Utilizing analytic hierarchy process to analyze consumers' purchase evaluation factors of smartphones. International Journal of Social, Behavioral, Educational, Economic, Business and Industrial Engineering, 7 (6), 1556-1561.

IDC (2019). Worldwide Quarterly Wearables Tracker, 20.06.2019 tarihinde https://www.idc.com/promo/wearablevendor adresinden erişilmiştir.

Kailiponi. P. (2010). Analyzing evacuation decisions using multi-attribute utility theory. Procedia Engineering, 3, 163-174.

Kaplanoğlu, E. (2019). Entropi tabanlı MAUT yöntemiyle performans ölçümü: MKEK fabrikalarının sıralanması. İşletme Ekonomi ve Yönetim Araştırmaları Dergisi, 1, 7 - 18.

Kazan, H. ve Özdemir, Ö. (2014). Financial performance assessment of large scale conglomerates via TOPSIS and critic methods. Journal of Management and Sustainability, 3(4), 203-224.

Keeney, R.L. ve Raiffa, H. (1976). Decisions with multiple objectives: preferences and value trade offs. John Wiley E Sons, New York. 
Kılıç, O. ve Çerçioğlu, H. (2016). TCDD iltisak hatları projelerinin değerlendirilmesinde uzlaşık çok ölçütlü karar verme yöntemleri uygulaması. Gazi Üniv. Müh. Mim. Fak. Dergisi, 31(1), 211-220.

Kiracı, K. ve Bakır, B. (2019). Critic temelli EDAS yöntemi ile havayolu işletmelerinde performans ölçümü uygulaması. Pamukkale Üniversitesi Sosyal Bilimler Enstitüsü Dergisi, 35, 157-174.

Konuşkan, Ö. ve Uygun, Ö. (2014). Çok nitelikli karar verme (MAUT) Yöntemi ve Bir Uygulamas1. Akademik Platform, 1403-1412.

Lopes, Y. G. ve Almeida, A. T. (2015). Assessment of synergies for selecting a project portfolio in the petroleum industry based on a multi-attribute utility function. Journal of Petroleum Science and Engineering, 126, 131140.

Madic, M. ve Radovanovic, M. (2015). Ranking of some most commonly used non-traditional machining process using ROV and CRITIC methods. U.P.B. Sci. Bull.. Series D., 77(2), 193-204.

Minacikova, E. (2016). Application of selected weighting methods and topsis method in regional disparities analysis. The 10th International Days of Statistics and Economics, Prague, 1241-1249.

Orakçı, E. ve Özdemir, A. (2017). Telafi edici çok kriterli karar verme yöntemleri ile Türkiye ve $\mathrm{AB}$ ülkelerinin insani gelişmişlik düzeylerinin belirlenmesi. Afyon Kocatepe Üniversitesi İ̈BF Dergisi, 19 (1), 61-74.

Organ, A. ve Kenger, M.D. (2017). Personel seçiminin entropi temelli maut ve gri ilişkisel analiz yöntemleri ile değerlendirilmesi. Current Debates in Business Studies. First Edition, Vol.1. December. İstanbul. 15-40.

Ömürbek, N. , Karaatlı, M. Ve Balcı H. F. (2016). Entropi temelli MAUT ve SAW yöntemleri ile otomotiv firmalarının performans değerlemesi. Dokuz Eylül Üniversitesi İktisadi ve İdari Bilimler Fakültesi Dergisi, 31(1), 227-255.

Perçin, S. ve Pancaroğlu, M.S. (2019). Akıllı telefon seçim faktörlerinin bütünleşik yapısal eşitlik modeli- analitik hiyerarşi süreci ile incelenmesi. Uluslararası İktisadi ve İdari İncelemeler Dergisi, 23, 113-130.

Suki, N. M. ve Suki, N. M.(2013). Dependency on smartphones: an analysis of structural equation modelling. Sains Humanika, 62 (1), 49-55.

Şahin, Y. ve Aydemir, E. (2019). Akıllı telefon teknik özellik önem derecelerinin AHP ağırlıklı gri ilişkisel analiz yöntemi ile belirlenmesi. Eskişehir Osmangazi Üniversitesi İ̈BF Dergisi, 14 (1), 225-238. 
Ünlü, U., Yalçın, N. ve Yağlı, İ. (2017). Kurumsal Yönetim ve Firma Performansı: TOPSIS Yöntemi ile BIST 30 firmaları Üzerine Bir Uygulama. Dokuz Eylül Üniversitesi Sosyal Bilimler Enstitüsü Dergisi, 19(1), 63-81.

Wang, C.H. (2015). A market-oriented approach to accomplish product positioning and product recommendation for smart phones and wearable devices. International Journal of Production Research, 53(8), 2542-2553.

Wang, J.-J., Jing, Y.-Y., Zhang, C.-F. ve Zhao, J.-H. (2009). Review on multicriteria decision analysis aid in sustainable energy decision-making. Renewable and Sustainable Energy Reviews, 13(9), 2263-2278.

Wang, M., Lin, S. J. ve Lo, Y. C. (2010). The comparison between MAUT and PROMETHEE. In Industrial Engineering and Engineering Management (IEEM). 2010 IEEE International Conference, 753-757.

Yalçın, N. ve Ünlü, U. (2018). A multi-criteria performance analysis of ınitial public offering (IPO) firms using CRITIC and VIKOR methods. Technological and Economic Development of Economy, 24(2), 534-560.

Yarlıkaş, S. (2018). Basketbol takımlarının teknik performanslarının CRITICMOOSRA yöntemi ile değerlendirilmesi. Journal of Social and Humanities Sciences Research, 5(29), 3848-3859.

Yılmaz, B. ve Harmancioğlu, N.B. (2010). Multi-criteria decision making for water resource management: a case study of the Gediz River Basin, Turkey. Water SA, 36(5), 563-576.

Zardari, N.H., Ahmed, K., Shirazi, S.M. ve Yusop, Z.B. (2014). Weighting Methods and Their Effects on Multi-Criteria Decision Making Model Outcomes in Water Resources Management. Springer.

Zietsman, J., Rilett, L. R. ve Kim, S. J. (2006). Transportation corridor decisionmaking with multi-attribute utility theory. International Journal of $\mathrm{Ma}$ nagement and Decision Making, 7(2-3), 254-266.

\section{Kaynakça Bilgisi / Citation Information}

Bulğurcu, B. (2019). Çok nitelikli fayda teorisi ile CRITIC yöntem entegrasyonu: Akıllı teknoloji tercih örneği.OPUS-Uluslararası Toplum Araştırmaları Dergisi, 13(19), 1930-1957. DOI: 10.26466/opus. 584123 